\title{
To what extent does the oral shift report stimulate learning among nursing
}

students? A qualitative study.

Mari Wolff Skaalvik, Hans Ketil Normann and Nils Henriksen

Mari Wolff Skaalvik, RN, RNT, Phd-student.

Department of Health and Care Sciences.University of Tromsø, Norway. N-9037 Tromsø, Norway.

Hans Ketil Normann, RN, RNT, PhD, Associate Professor. Department of Health and Care Sciences. University of Tromsø. Norway. N-9037 Tromsø, Norway.

Nils Henriksen, MSc, PhD, Associate Professor. Department of Health and Care Sciences. University of Tromsø. Norway. N-9037 Troms $\varnothing$, Norway.

Corresponding author: Mari Wolff Skaalvik. Department of Nursing and Health Sciences. University of Tromsø., N-9037 Troms $\varnothing$, Norway. Phone work:+00477764882. Cell phone: +004741587367. E-mail: Mari.Skaalvik@fagmed.uit.no

Manuscript accepted 31.10.09. Journal of Clinical Nursing. 


\section{Abstract}

\section{Aim and objective}

The aim of this study was to describe oral shift reporting and to discuss whether it stimulates learning for nursing students in clinical rotations in nursing homes. The goal was to investigate aspects that are important for oral shift report to be instructive for nursing students

\section{Background}

Nursing students' clinical learning experiences are important components of their professional development. Oral shift reporting serves several purposes and provides an opportunity for professional communication that supports both educational and social functions for nursing students during clinical practice.

\section{Design}

A qualitative study.

\section{Methods}

The study features both field work with field notes and qualitative research interviews was conducted in 2006. Twelve third-year nursing students and their supervising nurses $(n=11)$ participated in the study.

\section{Results}

The nursing students described a range of experiences with oral shift reports. Some perceived little educational benefit from the oral shift reports, while others felt that both the form and content of the oral shift reports were useful. The students' experiences corroborated the statements provided by the supervising nurses in the nursing homes.

\section{Conclusions}

We conclude that oral shift reporting may be an important learning opportunity. This is especially true when nursing students engage in professional discussions with their colleagues 
and superiors. Our findings suggest solutions to improve the learning value of the oral shift reporting process for nursing students.

\section{Relevance to clinical practice}

Oral shift reporting can stimulate learning if it includes consultation and discussion between nursing students and the nursing staff.

\section{Keywords}

Oral shift report, handover, nursing home, older people care, nursing student, learning. 


\section{What is known about this topic}

- Oral shift report can serve educational, emotional, social and organisational purposes.

- Oral shift reporting can facilitate interpersonal communication and reflection.

- Silent report has become more prevalent in nursing practice.

\section{What this paper adds}

- Oral shift reporting, including professional discussions, can help with nursing students' learning.

- Nursing student who consider the shift report to be instructive achieved better learning outcomes.

- Effective use of oral shift reporting to support learning requires systematic management and good leadership.

\section{Implications for practice}

- The content and form of oral shift report must be adjusted to educational purposes.

- Measures for oral shift reporting to be instructive must be implemented in sites for nursing students' clinical practice.

- There is need of an awareness of the oral shift report's significance as a situation for learning. 


\section{INTRODUCTION}

Clinical practice is a component of nursing education that helps students to develop independent professional expertise and also promotes role socialisation (Papp et al. 2003, Myrick et al. 2006). The purpose of this hands-on component is to refine practice skills including critical thinking, clinical judgement and the use of holistic patient care. In clinical practice, each student should receive clinical teaching, supervision, support and assessment to facilitate learning (Ministry of Education and Research 2004).

Nursing students' (NSs) clinical experiences are important to their professional development. Through clinical practice in nursing homes (NHs), students prepare themselves to enter complex practice communities (Wenger 1998). Supervising professionals function as resources for the learning process and as role models in the preparation and delivery of care and socialisation (Kilcullen 2007). Clinical practice requires that students demonstrate the ability to observe, reflect, analyse and systematise from both theoretical and clinical standpoints (Ministry of Education and Research 2004). To achieve this, NSs must be allowed to participate in relevant nursing care scenarios that integrate theory and clinical practice.

The oral shift report (OSR) is an inter-shift report, also called a report handover (Eggland \& Heineman 1994) that normally takes place in the morning, afternoon and evening. The purpose of the OSR is to transfer information from the outgoing staff to the incoming staff (Hays 2002). The OSR is a complex and important part of nursing practice that serves several purposes, including the provision of updated information, continuity and quality of patient care (Sherlock 1995, Meizner et al. 2007), as well as assignment of responsibilities and routine tasks. 
Studies of OSR have primarily addressed their type, duration, content and rituals (Taylor 2002). Some studies have emphasised the complexity of OSR and recent attempts to question its role as a potential learning and teaching situation (cf. Sherlock 1995, Thurgood 1995, Payne et al. 2000). During the working day in NHs, NSs regularly encounter oral shift reporting. In addition to serving as instructional tools for NSs, OSR also aids the preparation and delivery of nursing care.

OSR may assist NSs with education, social interaction, emotional support and socialisation into the professional nursing role (Kerr 2002). Gundersen (1997) and Payne et al. (2000) reported that OSR facilitates interpersonal communication and reflection and is an important learning situation in the sense that aspects of patient care can be articulated and discussed. In addition, it helps with the transfer and exchange of knowledge.

During OSR, students' understanding and assessment of nursing care can be expanded and related to both practical and theoretical knowledge. In OSR, attitudes can be disseminated, developed and adjusted as different elements of a patient's situation are discussed. If OSR is used to its full potential, it constitutes an essential learning situation for NSs (cf. Hamran 1991) by providing person-centred perspectives (Kitwood \& Bredin 1992) regarding the provision of patient care. Incorporating teaching in the OSRs can enhance their role in the NSs' learning experience. The NSs' curriculum includes learning objectives related to caring for older people, interaction between patient and nurse, problem solving, communication, documentation, management and the general organisation of nursing care (Ministry of Education and Research 2004). 


\section{Aim of the study}

The aim of the study was to describe OSR and discuss whether it provides learning opportunities for nursing students undertaking clinical placements in nursing homes as part of their training.

\section{Material and methods}

A qualitative design (cf. Polit \& Beck 2008) including field observations, field notes and qualitative research interviews (cf. Hammersley \& Atkinson 1990) was used in this study. Field observations helped to identify practice in both a structural and a cultural context (Hammersley \& Atkinson 1990, Polit \& Beck 2008). Qualitative interviews provided the means to examine the subjective experiences and perceptions of individuals (Graneheim \& Lundman 2004). At the end of the clinical practice, semi-structured interviews (Kvale 2001) were conducted with each participant. Relevant literature was sourced from Cinhal, ProQuest and PubMed by combining the following keywords: oral shift report, handover, nursing home, care for older people, nursing student and learning.

\section{The contexts of the study}

We focused on three NHs in Norway that are part of the municipal health care service and were founded following The Act of Health Care Services in the Municipalities (Ministry of Health and Care Services 1982). The NHs had been used as sites for clinical placements on a regular basis for several years through a mutual agreement between the university and the local municipality. The NHs included in this study are the NHs which were used for clinical practice for the participating NSs at the time of the study. The leaders of the NHs allowed the first author to be present during OSRs and make field notes. 
No workload statistics were available for these NHs. Nursing staff reported that all patients needed help completing their daily activities. They estimated that $80 \%$ of the patients suffered from cognitive impairments, although not all had been diagnosed with Alzheimer' disease (AD). This is consistent with the percentage cited in a report from the Directorate for Health and Social Affairs (2007). There were no significant differences between the three NHs with respect to the staff/patient ratio (3/9). OSRs were conducted in the duty room at the NHs . They were conducted in the morning, afternoon and evening. According to the schedule, 30 minutes were allotted for OSR in the morning and in the afternoon.

Seven students (1-7) were assigned to the first NH (A) for their clinical practice; two students were stationed on each of three wards and one student was assigned to a fourth unit. On these wards, OSRs normally lasted ten minutes. Care plans were not used as a basis for the reports and the reporting nurse mostly read from a handwritten self-adhesive note or presented memorised information about elimination, sleep, rest or unrest for a small number of patients.

Two students (8 and 9) undertook their clinical practice in the second NH (B). One student (8) was stationed on a sheltered ward for patients suffering from advanced AD. In this ward, the 30 minutes allotted for OSR were fully used and extended if necessary. Reports were based on care plans that included information about the physical and psychosocial conditions of all patients. Reports from the perspective of the individual patient were also used. Another student (9) was assigned to a general ward. On this ward, the average time spent on OSR activities was ten minutes. Care plans were not used as a basis for these brief reports. Nurses simply focused on physical parameters like elimination, sleep and rest for a limited number of patients. 
Three students (10, 11 and 12) were placed in the third NH (C) which was part of a healthcare centre. The institutional portion of the centre comprised an $\mathrm{NH}$ unit and a general practitioner hospital (GPH) unit. Oral shift reporting nominally lasted 30 minutes, but this period was extended if necessary. Care plans were used as the basis for person-centred reports. Nurses reported on both the physical and psychosocial conditions for all patients and often included statements about the responses of the patients.

\section{Participants}

We enrolled in our study all final third year NSs $(n=13)$ in the university who undertook ten weeks of clinical practice involving care of older people. One student dropped out, leaving 12 participants. The students had previously completed six weeks of general clinical nursing practice in NHs during their first year of study. Eleven nurses who served as supervising nurses (SNs) for the NSs in one-to-one relationships also participated in our study. One SN acted as a supervisor for two students. The SNs were experienced supervisors but held no formal supervisory qualifications. They were informed in writing and in a preparatory meeting about the NSs' learning requirements. No specific supervisory guidelines were given. The SNs were expected to practice nursing care together with the NSs and to initiate counselling according to learning objectives and practical experiences. In-service training was given on a regular basis on gerontological topics. The first author had no prior relationship with the students and did not hold any professional role in the students' clinical placements.

\section{Data collection}

Data was collected in 2006. Field observations with field notes (Hammersley \& Atkinson1990) focused on oral shift reports in the duty room during the NSs' ten weeks of clinical practice. The observation period was divided between the three NHs according to the 
number of students at each location. The field observations of oral shift reporting were performed in the mornings and in the afternoons when NSs were present. Observations were centred on content, focus, duration and participation. The technique described by Schatzman and Strauss (1973) was used when taking field notes in the form of observational, theoretical, methodological and personal descriptions. Field notes were transcribed on a daily basis following data collection.

At the end of the clinical period, semi-structured interviews (Kvale 2001) were conducted with each participant. These interviews included questions to explore OSR as an aid to learning. An interview guide was developed with thematic questions, including OSR-relevant prompts from other research studies (Liukkonen 1992, Gundersen 1997, Payne et al. 2000, Kerr 2002) and from observations of the NH reporting sessions. During the interviews, the first author posted an introductory open question (cf. Kvale 1997) to the NSs and the SNs about OSR with respect to learning: 'Could you tell me about whether you consider the OSR to be helpful for teaching and learning?' The interviews lasted between 40 and 70 minutes and took place toward the end of the clinical practice period. The interviews were audio recorded and transcribed verbatim.

\section{Data analysis}

Field notes were analysed by the first author using the procedure described by Hammersley and Atkinson (1990), starting with broad descriptive categories and sorting the material in relation to content, focus, duration and OSR participation. The interviews were analysed using qualitative content analysis. The transcriptions were read and reread to grasp a thorough understanding of each individual interview. After the NS interviews, a condensation step was performed to determine units of meaning by classifying constellations of words related to the 
same central themes (cf. Graneheim \& Lundman 2004). Our analysis of the NS interviews served as the basis for a selective approach (cf. Polit \& Beck 2008) that involved extracting the themes that were common across the SNs' statements and the phrases in the field notes.

\section{Ethical considerations}

The study was approved by the Norwegian Social Science Data Service. The heads of the NHs gave written permission for the field observations. The participants received an explanatory letter about the study and were invited to participate. Informed written consent was obtained before data collection began. Participants were assured that involvement was voluntary and that they had the right to withdraw from the study at any time without consequence or the need to state a reason. Anonymity and confidentiality were guaranteed in any publication of the results. Participants were also informed that the audio recordings and transcriptions would be destroyed on completion of the study.

\section{RESULTS}

Several intertwined factors played a role in how students perceived the OSR as a learning environment. Seven sub-themes were constructed from the NS interviews. They were abstracted and grouped under three main themes:

- the oral shift report as a context for professional discussions

- the content of oral shift reports

- the oral shift report in the context of learning 
The textual findings are presented in terms of NS experiences regarding the main themes. They are illustrated with quotations from students and SNs along with field observations as reported by the first author.

\section{The oral shift report as a context for professional discussions}

The NSs saw professional discussions with staff - especially their SNs - as very helpful in stimulating learning. However, their experiences of these discussions were variable. One student (5) said: 'I wish there were more professional discussions during reports because I would learn more.' Another student (1) said: 'The routines are very entrenched here and there are few professional discussions during reporting sessions.' This statement was supported by another student (2) who told that: 'Attempts to encourage professional discussions are mostly futile.' Another student (7) said: 'If I try to raise a professional issue during reports I feel like it is normally perceived as criticism.' The NSs seemed to try to compensate for the lack of professional discussions during OSRs by engaging in similar discussions with fellow students. One student (4) stated: 'We (students) discuss our experiences, but they (the staff) are not really interested.' Other students had different experiences. One student (12) said: 'There are many good discussions during reporting sessions', while another (10) said: 'During reporting sessions all patients are discussed and this results in good, professional dialogue that helps me learn.'

In seeing OSR as an arena for professional discussions and learning, the NSs expected to be engaged in planning and assessing patient care. They thought that they would be asked about their knowledge and they expected that their comments would receive attention during OSRs. However, one student (6) said: 'During reporting sessions, the staff never ask for my point of 
view.' Others had more positive experiences; one student (12) said: 'We are always being challenged and listened to during reporting sessions.'

Differences in student experiences with respect to professional discussions during OSRs were expressed by their SNs. One nurse (5) said: 'The reporting sessions could have been better.' This was substantiated by another SN (4) who stated: 'We try to address various issues, but reporting sessions are too short.' One SN (3) said: 'We should have had more discussion.' Another SN (8) said: 'In the morning report I follow up issues and relay announcements. In the afternoon we just hand over the ward as the staff is in a rush to get home.' In NH B, SN (9) said: 'I bring up different issues during reporting sessions and discussions follow from there.' One SN (11) said: 'We place an emphasis on professional discussions and we spend as long as is necessary to ensure good report quality.'

Based on the observations and field notes made by the first author, the experiences of the students and the statements from the SNs appeared to be consistent. OSR content with respect to professional discussions varied from being almost non-existent to being a significant focus of each reporting session. On the wards where professional discussions hardly ever occurred, OSRs were very brief, lasting approximately ten minutes without the use of care plans. It was clear that incoming staff on these wards rarely took notes on what was reported. Distribution of tasks was based on routines rather than care issues and was not normally discussed, unless staff shortage required specific schedule adjustments. On these wards, the NSs were silent and uninvolved during the reporting sessions.

On certain wards, the scheduled time for OSR was fully used and was sometimes extended because of discussions that required additional time. On these wards, OSRs were based on 
care plans and incoming staff took notes on a sheet of paper for use during their shifts.

Students took the initiative during OSRs on these wards and they were actively asked about their opinions regarding care options for specific patients. In addition, students were given opportunities to share their knowledge regarding any issues that arose. Discussions also dealt with how the NS learning objectives could best be met. In NH C, the leader was present at all daytime OSRs. During OSRs, this leader created time-outs on a regular basis when subjects suitable for critical reflection, teaching and learning were brought up.

\section{The content of the oral shift reports}

The OSR has several purposes, such as to plan care and distribute tasks to promote quality and continuity of patient care. One NS (9) said: 'Reporting periods deal with practical issues and necessary observations.' Another student (3) said: 'During reporting periods one briefly talks about any unusual patient status information and offers practical instructions, for example that incontinence diapers are being used too regularly.' Such experiences were not noted by students on other wards as one response (10) indicates: 'During reporting sessions all patients are discussed both in terms of what has happened as well as what will happen in the near future... and during reporting periods the staff encourage and remind each other of issues that are important for high quality care.'

The SNs reported experiences and perceptions regarding the content of OSRs that mostly corroborated those cited by the students they supervised. An SN (1) said: 'In reporting sessions it is a challenge...to know what to include and what to leave out.' Another SN (10) said: 'In oral shift reporting, we are strict about distinguishing between small talk and professional issues. The time for OSR is spent on issues that are of relevance for patient care.' This statement was representative of OSRs that the NSs found instructive. 
The differences in the experiences of the NSs corroborate observations made by the first author. Reports on certain wards were brief, only mentioning conditions like elimination, sleep, unrest and medications among a few patients before the staff started the working day by engaging in patient care based on non-communicated reasoning and routines. Words like 'fine', 'difficult' and 'nothing unusual' were often used. This contradicted observations from $\mathrm{NH} \mathrm{C}$ and from the sheltered ward in NH B where reporting sessions were often extended as necessary. Staff would discuss all of the patients, both in retrospect and in prospective care planning and also engaged in discussions of general nursing care practices. Another significant difference was that in these sites psycho-social dimensions and patient-reported issues were emphasised. Thus, the staff took into account not only the nurses' views but also the patients' perspectives. In these sites, students were engaged as active OSR participants. They were asked about care options and were encouraged to actively participate in nursing activities.

\section{The oral shift report in the context of learning}

The NSs expected that, through the clinical placement, they would become better qualified nurses and would be able to promote high quality care through planning and assessment. Consistent with their expectations, they saw the OSR as a meaningful learning situation. Regarding OSR as instructive, the following statement (4) was representative of the experiences of several students: 'Reporting at this facility does not lead to a meaningful learning experience because the reporting sessions are too brief and superficial.' The perceptions of the SNs corroborated these opinions. One SN (6) stated: 'We don't have enough time to perform thorough reporting.' This statement is consistent with the perceptions of other SNs who considered that time was a limiting factor in ensuring high-quality OSRs. 
Other students experienced the opposite. For instance one NS (11) said: 'I have learned a lot from the reporting sessions', and another (8) stated: 'At this facility reporting periods are used as an opportunity for everyone to learn, not just students.' The nurses who supervised these NSs offered insights into the use of reporting sessions for teaching and learning. One SN (9) said: 'We have thorough person-centred reporting that focuses on every patient on the ward, including both their physical and their psychosocial needs. Students can learn from these discussions.' Another SN (7) said that: 'We conduct the reports even more stringently when we have students here'. This statement was elaborated when the SN added: 'They (the students) should learn from participating in the reporting sessions.'

The experiences and perceptions of the students regarding OSR learning outcomes are consistent with observations made by the first author. In NH A and in the general ward in $\mathrm{NH}$ B that conducted only the briefest OSRs, there were few discussions and minimal question time or critical reflection time to investigate patients or issues concerning person-centred care. The approach was more routine - and task-orientated.

On the wards where the OSRs were patient-centred, issues regarding certain conditions and prospective patient care often resulted in communication that included theoretical knowledge, assessment and shared learning to promote quality of care. On these wards, the OSR sessions included opportunities for the students to talk about their experiences and receive emotional support to improve their reactions to clinical situations. This directly facilitated the learning process. 


\section{DISCUSSION}

Several studies state that shift reporting may promote learning (Sherlock 1995, Lamond 2000, Kerr 2002). NSs' perceptions of OSR as a learning situation varied in our study. Their experiences were consistent with both the statements offered by the SNs and the observations recorded in the field notes. The main themes from the NS interviews highlight the challenges associated with establishing structures and routines for instructive OSRs with professional discussions, social interaction and emotional support.

Student expectations of OSR with respect to professional discussion opportunities relate to several phenomena in nursing practice. NSs are new, temporary members of the nursing community during their clinical placements. The OSR allows students to become integral members of the nursing community. To learn from experience, students need to participate in dialogue with experienced nurses about their approaches to patient care. This helps the students develop understanding and nursing insights. Support of NSs' learning processes requires adjustments to the OSR on some of the wards in our study. Several deliberate adjustments were made in NH C and on one ward in NH B. These adjustments positively impacted NS learning outcomes and also benefited the nursing staff in general.

Some studies have shown that NSs may see caring for older people as tedious, boring and professionally unchallenging (Lovell 2006, Kloster et al. 2007). In caring for older people, students experience situations that can affect them emotionally such as patients suffering from $\mathrm{AD}$, deviant behaviour and dying patients. This may cause the students to experience stress and anxiety (Beck 1996). Thurgood (1995) points to OSR as one means of sharing experiences to alleviate stress and anxiety. 
As part of their learning process, students must be exposed to scenarios where physical, psychosocial, emotional and practical issues in nursing care are raised and discussed. Using the OSR for professional discussions is one possible approach. Task orientation in the OSR, may have consequences for student' perceptions of nursing care values. A study by Smith (1992) shows that students need appropriate guidance and support if they are to nurse flexibly and with sensitivity. The OSR offers the possibility of supporting such NS needs.

The NSs in our study expected to be given opportunities during OSR to disseminate their knowledge and points of views regarding nursing care. In addition, they saw OSRs as particularly constructive when material they had learnt was questioned. If these events are absent from clinical placements, students may develop practice routines that are never critically evaluated. Consequently, their development as critical and reflective practitioners (cf. Schön 1983) may well be impaired. In contrast, the ideal situation is one in which students experience learning and socialisation into a professional nursing role through personcentred individualised OSRs (cf. Yurkovich \& Smyer 1998).

The condition of NH patients does not usually change drastically from day to day (Liukkonen 1993) and this may be one reason why OSRs on some wards tended to be brief and included only limited communication about the patients' needs. Brief OSRs may be appropriate for the regular staff as patient needs and tasks appear obvious to them. However, such brief OSRs may limit the learning possibilities for NSs. Articulation of seemingly standard knowledge and the development of mutual understanding is important for NSs since they are novices (Benner 1984) who are still in the early stages of professional development. Unarticulated knowledge may exclude students who are new and temporary members of the nursing community. 
For the NHs included in this study, reliance on mutual knowledge and understanding seemed to be standard practice on those wards that featured brief and seemingly superficial communication during OSRs. Person-centred communication was instead primarily observed during spontaneous encounters while on shift. They practiced alone, therefore, students were seldom included in such communications (cf. Fagermoen \& Nygård 1989).

In $\mathrm{NH} \mathrm{C}$ and on the sheltered ward in $\mathrm{NH} \mathrm{B}$, students experienced and participated in OSRs that were instructive and supported the development of professional sensitivity and appropriate attitudes regarding care for older people. Oral shift reporting was conducted in a dialogue-driven manner that delivered value premises and refined the understanding and skills that are relevant to quality nursing care. In both this $\mathrm{NH}$ and on the sheltered ward, it was observed that staff members took notes during OSRs as 'scraps' (cf. Hardey et al. 2000) for use in their care for the patients.

Meizner et al. (2007) found that the percentage of nurses in ten European countries who reported being dissatisfied with their OSR processes ranged from $22 \%$ in England to $61 \%$ in France. In this study, the SNs on wards that conducted brief, task-orientated OSRs, stated that they saw a potential for improvement. They commented that the lack of time and the uncertainty regarding relevant OSR-content were the major reasons for unsatisfactory OSRs.

Norberg and Asplund (1987) concluded that the length of reporting on psycho-geriatric wards for patients suffering from AD varied from 5-21 minutes with a mean duration of 10 minutes. This is consistent with some of our findings in which the NSs were dissatisfied with OSR sessions that they perceived as only offering limited learning opportunities. Norberg andAsplund (1987) found that the reports focused on problems with elimination, 
communication, personal hygiene and sleep. This coincides with some of the findings in our study, except for the fact that communication with the patients was rarely dealt with on those wards that relied on brief, summary reporting.

The traditional OSR has been criticised for being time consuming and inefficient (Bø 2007). A change from face-to-face OSR to silent reporting has been implemented in many healthcare settings in an attempt to increase efficiency (Pollitt \& Bouckhaert 2000). From the perspective of OSRs as situations for NS learning, silent reporting seems disadvantageous. NSs need to learn from dialogue and critical reflection (cf. Schön 1983) with expert nurses.

On the wards where the NSs believed that OSR offered meaningful learning experiences, field observations showed that person-centred reports placed equal emphasis on physical, social and psychological aspects such as communication and the feelings expressed by patients. The OSRs on these wards included time for in-depth elaborations of the issues at hand. Because many $\mathrm{NH}$ patients suffer from cognitive impairments, addressing the psychosocial aspects of care can be vital. A study by Lindgren and Murhy (2002) concluded that family and staff are often concerned about socio-emotional care for $\mathrm{NH}$ residents.

\section{Trustworthiness and limitations}

Trustworthiness was established through method triangulation (Polit \& Beck 2008) by using multiple data collection methods to investigate whether OSR sessions were instructive. The co-authors checked the reliability of the data by comparing interpretations of the data. Morse and Field (1996) wrote about possible change in behaviour when an observer is present. The first author's experience was that most participants were not influenced by the presence of the observer during oral shift reports. 
The small sample and the qualitative approach in this study limit the generalisability of our findings. One must be cautious in drawing conclusions from a study conducted across only three NHs. One site was a GPH and another site a sheltered ward for patients suffering from advanced AD. These factors must also be taken into consideration. Although the study only examined the OSR practices in Norwegian nursing homes for a small number of participants over a short time period, our findings may nonetheless be applicable and relevant to other contexts involving NSs' clinical practice and learning.

\section{Conclusions}

It is broadly accepted that OSR can be a meaningful learning opportunity in clinical practice. From the findings in our study this is especially true for OSR given appropriate content, time, sufficient professional discussions and patient-centred focus. However, some of the findings from this study seem to suggest that there exists potential for improvement. Discussions of the psychosocial dimensions of patient care and physical issues must be given the necessary time in OSRs. To provide educational opportunities, oral shift reports must emphasise both retrospective and prospective issues of relevance to patient care. The use of labelling phrases (cf. Sherlock 1995) like 'fine' and 'difficult' must be avoided as should statements such as 'nothing unusual to report'. In assigning students to clinical placements, the ward leader has a special responsibility for explicitly teaching students by using examples and by contributing to the integration of theory and practice. A designated and responsible leader is therefore essential. If the NSs are to learn from OSRs, they must be engaged throughout these sessions. Uncertainty about what to include in the OSR, requires that we investigate how it can be improved to increase the instructive value for NSs. 


\section{Relevance to clinical practice}

Efforts to establish a ward culture dedicated to and supportive of the quality of NS clinical learning processes, must be acknowledged and implemented in practice. Measures for conducting instructive OSRs must be implemented as part of the responsibilities in allocating clinical placements for nursing students. The change from OSR to silent reporting in nursing practice may represent the loss of a unique learning situation for NSs. The positive experiences of some of the participants in this study underline the learning advantages of oral shift reports.

\section{Acknowledgements}

The authors wish to thank the participants from the nursing homes for permitting us to conduct this research. Furthermore, we wish to thank the participating nursing students and supervising nurses for their generosity and openness during the interviews.

\section{Funding}

The study is funded through a scholarship at the University of Troms $\varnothing$, Faculty of Health Sciences, Department of Health and Care Sciences.

\section{Contributions}

Study design: MWS, HKN, NH.

Data collection: MWS

Data analysis: MWS, NH, HKN

Manuscript preparation: MWS, HKN, NH.

Conflict of interest: There are no conflicts of interest regarding financial or personal interests. 


\section{References}

Beck CT (1996) Nursing students' experiences caring for cognitively impaired elderly people. Journal of Advanced Nursing 23, 992-998.

Benner P (1984) From Novice to Expert: Excellence and Power in Clinical Nursing Practice. Addison-Wesley, Reading, Mass.

Bloom BS (1964) Stability and change in human characteristics. John Wiley and Sons Inc., New York. London. Sydney.

Bø B (2007) Shift report. Oral report and silent report; benefits and disadvantages. Nursing experiences. Post graduate thesis in nursing sciences. Section of Nursing Sciences. Bergen University. Bergen. (In Norwegian).

Directorate for Health and Social Affairs (2007) Forgetful, but not forgotten. Current situation and future challenges in strengthening services to persons suffering from dementia. Rapport 15-1486. Oslo. (In Norwegian).

Eggland ET \& Heinemann DS (1994) The reporting process. In Nursing documentation, (Hilton DL \& Ryalls B eds.), J B Lippincott, Philadephia, pp. 209-223.

Fagermoen MS \& Nygård AK (1989) Clinical practice: a place for learning or a place of residence? Sykepleien 77, 4-8. (In Norwegian). 
Graneheim UH. \& Lundman B (2004) Qualitative content analysis in nursing research: concepts, procedures and measurements to achieve trustworthiness. Nurse Education Today $24,105-112$.

Gundersen S (1997) Report -an arena for reflection. Master of Science Thesis. Section of nursing and health care sciences. Oslo University, Oslo. (In Norwegian).

Hammersley M \& Atkinson P (1996) Ethnography. Principles in practice. Routledge, London.

Hamran T (1991) The limits of effectiveness. Can communication technology replace oral shift report in a hospital ward? In: Between ideals and realities. Studies in medical sociology (Album D \& Midrés G eds.). Ad Notam, Oslo. pp 55-84. (In Norwegian).

Hardey M, Payne S \& Coleman P (2000) 'Scraps': hidden nursing information and its influence on the delivery of care. Journal of Advanced Nursing 32 (1), 208-214.

Hays M M (2002) An Exploratory Study of Supportive Communication During Shift Report. Southern Online Journal of Nursing Research (www.snrs.org) 3 (3). Retrieved 12.02.08.

Heggen K (1995) The hospital as classroom. Universitetsforlaget, Oslo. (In Norwegian).

Kerr MP (2002) A qualitative study of shift handover practice and function from a sociotechnical perspective. Journal of Advanced Nursing 37 (2), 125-134. 
Kilcullen NM (2007) Said Another Way: The Impact of Mentorship on Clinical Learning. Nursing Forum 42 (2).

Kitwood T \& Bredin K (1992) A new approach to the evaluation of dementia care. Journal of Advanced Health and Nursing Care 1, 41-60.

Kloster T, Høie M \& Skår R (2007) Nursing students’ career preferences: A Norwegian Study. Journal of Advanced Nursing 58 (3), 1-8.

Kvale S (2001) The qualitative research interview. Gyldendal Akademisk, Oslo. (In Norwegian).

Lamond D (2000) The information content of the nurse change of shift report: a comparative study. Journal of Advanced Nursing 31 (4), 294-804.

Lindgren CL \& Murhy AM (2002) Nurses’ and Family Members' Perceptions of Nursing Home Residents' Needs. Journal of Gerontological Nursing 28 (8), 45-53.

Liukkonen A (1993) The content of nurses' oral shift reports in homes for elderly people. Journal of Advanced Nursing 18, 1095-1100.

Lovell M (2006) Caring for the elderly: Changing perceptions and attitudes. Journal of Vascular Nursing 24 (1), 22-26. 
Meizner A, Hasselhorn HM, Estryn-Behar M, Nézeto O, Pokorski J \& Gould D (2007)

Nurses' perception of shift handovers in Europe - results from the European Nurses' Early

Exit Study. Journal of Advanced Nursing 57 (5), 535-542.

Ministry of Education and Research (2004) National Curriculum Regulations for Nursing Programmes. Norway.

Ministry of Health and Care Services (1982) The Act of Health Care Services in the Municipalities. Last revised 22.12.2006. Ministry of Health and Care services in the Municipalities. Oslo.

Morse J \& Field P (1996) Nursing Research: The Application of Qualitative Approaches. Croom Helm, London.

Myrick F, Phelan A, Barlow C, Sawa R, Rogers G \& Hurlock D (2006) Conflict in the preceptorship or field experience: A rippling tide of silence. International Journal of Nursing Education Scholarship 3 (1). http://www.bepress.com/ijnes/vol3/iss1/art6. Retrieved 11.01.09.

Norberg A \& Asplund K (1987) Patterns of speech. Nursing Times. 83, 64-66.

Papp I, Karkkanen M \& van Bonsdorff M (2003) Clinical Environment as a learning environment: student nurses' perceptions concerning clinical learning experiences. Nurse Education Today 23 (49), 262-268. 
Payne S, Hardey M \& Coleman P (2000) Interaction between nurses during handovers in elderly care. Journal of Advanced Nursing 32 (2), 277-285.

Pollitt C \& Bouckhaert G (2000) Public Management Reform: A Comparative Analysis. University Press, Oxford.

Polit D \& Beck C (2008) Nursing Research. Generating and Assessing Evidence for Nursing Practice $\left(8^{\text {th }}\right.$ ed.) Lippincott Williams and Wilkins, Philadelphia.

Schatzman L \& Strauss A (1973) Field Research.Strategies for a Natural Sociology. PrenticeHall, Inc., Englewood Cliffs, New Jersey.

Sherlock C (1995) The patient handover: a study of its form, function and efficiency. Nursing Standard 9 (52), 33-36.

Schön D (1983) The reflective practitioner. How professionals think in action. Basic Books, New York.

Smith P (1992) The Emotional Labour of Nursing. The Macmillan Press, Basingstoke.

Taylor C (2002) Assessing patients' needs: does the same information guide expert and novice nurses? International Nursing Review 49, 11-19.

Thurgood G (1995) Verbal handover reports: what skills are needed? British Journal of Nursing 4 (12), 720-722. 
Wenger E (1998) Communities of Practice. Learning, meaning and Identity. Cambridge University Press, New York

Yurkovich E \& Smyer T (1998) Shift report: A time for learning. Journal of Nursing Education 37 (9), 401-406. 
Table 1. Participants and nursing homes included in the study.

\begin{tabular}{|l|l|l|l|}
\hline & Ward & Students & Supervising nurses \\
\hline Nursing home A & 1 & 1,6 & 1,2 \\
\hline & 2 & 4,7 & 3 \\
\hline & 3 & 5 & 4 \\
\hline & 4 & 2,3 & 5,6 \\
\hline Nursing home B & 1 & 8 & 7 \\
\hline & 2 & 9 & 8 \\
\hline Nursing home C & 1 & $10,11,12$ & $9,10,11$ \\
\hline
\end{tabular}

Table 2. Examples of the process of qualitative content analysis.

\begin{tabular}{|c|c|c|c|c|}
\hline Meaning unit & Condensation & Sub-themes & Theme & Main theme \\
\hline $\begin{array}{l}\text { I wish there were more } \\
\text { professional discussions } \\
\text { during reports because I } \\
\text { would learn more }\end{array}$ & $\begin{array}{l}\text { The NS recognize } \\
\text { professional discussions } \\
\text { as a potential for } \\
\text { learning }\end{array}$ & $\begin{array}{l}\text { Being dissatisfied with } \\
\text { OSR because of absence } \\
\text { of professional } \\
\text { discussions }\end{array}$ & $\begin{array}{l}\text { Limited learning from } \\
\text { professional discussions } \\
\text { during OSRs }\end{array}$ & $\begin{array}{l}\text { The oral shift report as a } \\
\text { context for professional } \\
\text { discussions }\end{array}$ \\
\hline $\begin{array}{l}\text { During reporting periods } \\
\text { one briefly talks about } \\
\text { any unusual patient } \\
\text { status information and } \\
\text { offers practical } \\
\text { instructions, for example } \\
\text { that incontinence diapers } \\
\text { are being used too } \\
\text { regularly }\end{array}$ & $\begin{array}{l}\text { The reports as } \\
\text { summarily }\end{array}$ & $\begin{array}{l}\text { Dissatisfied with OSRs } \\
\text { having a retrospective } \\
\text { and practical focus }\end{array}$ & $\begin{array}{l}\text { Experiences of the } \\
\text { content in OSRs in } \\
\text { respect of learning }\end{array}$ & The content of the OSRs \\
\hline $\begin{array}{l}\text { Reporting at this facility } \\
\text { does not lead to learning } \\
\text { experiences because the } \\
\text { reporting sessions are } \\
\text { too brief and superficial }\end{array}$ & $\begin{array}{l}\text { Lack of learning from } \\
\text { reports }\end{array}$ & $\begin{array}{l}\text { Dissatisfaction with } \\
\text { OSRs as a situation for } \\
\text { learning }\end{array}$ & $\begin{array}{l}\text { Experiences regarding } \\
\text { OSRs as instructive or } \\
\text { not }\end{array}$ & \multirow[t]{2}{*}{$\begin{array}{l}\text { The oral shift report in } \\
\text { the context of learning }\end{array}$} \\
\hline $\begin{array}{l}\text { At this facility reporting } \\
\text { periods are used as an } \\
\text { opportunity for everyone } \\
\text { to learn, not just students }\end{array}$ & $\begin{array}{l}\text { Reports experienced as } \\
\text { instructive }\end{array}$ & $\begin{array}{l}\text { The aspect of learning is } \\
\text { integrated in the OSRs }\end{array}$ & $\begin{array}{l}\text { OSRs function regarding } \\
\text { common professional } \\
\text { learning }\end{array}$ & \\
\hline
\end{tabular}

Table 3. Sub-themes, themes and main-themes in the qualitative content analysis.

\begin{tabular}{|c|c|c|}
\hline Sub-themes & Themes & Main-themes \\
\hline $\begin{array}{l}\text { Being dissatisfied with ORS because of } \\
\text { absence of professional discussions } \\
\text { Compensate missing professional } \\
\text { discussions with nursing staff by discussing } \\
\text { with fellow students. } \\
\text { Being satisfied with OSRs as instructive } \\
\text { because they include professional } \\
\text { discussions }\end{array}$ & $\begin{array}{l}\text { Limited learning from professional } \\
\text { discussions during OSRs }\end{array}$ & $\begin{array}{l}\text { The oral shift report as a context for } \\
\text { professional discussions }\end{array}$ \\
\hline $\begin{array}{l}\text { Experiences OSRs as brief and superficial } \\
\text { Experiences of OSRs as thorough in } \\
\text { respect of being person-centred }\end{array}$ & $\begin{array}{l}\text { Experiences of the content in OSRs in } \\
\text { respect of learning }\end{array}$ & The content of the oral shift report \\
\hline $\begin{array}{l}\text { Experiencing limited learning form OSRs } \\
\text { Being satisfied with OSRs as instructive }\end{array}$ & $\begin{array}{l}\text { Experiences regarding OSRs as instructive } \\
\text { or not }\end{array}$ & $\begin{array}{l}\text { The oral shift report in the context of } \\
\text { learning }\end{array}$ \\
\hline
\end{tabular}

